\title{
Identification and Characterization of $\alpha$-Glucosidase Inhibition Flavonol Glycosides from Jack Bean (Canavalia ensiformis (L.) DC
}

\author{
Anita M. Sutedja ${ }^{1,2,3} \mathbb{D}$, Emiko Yanase ${ }^{1, *}$, Irmanida Batubara ${ }^{4,5}$, Dedi Fardiaz ${ }^{2}$ \\ and Hanifah N. Lioe ${ }^{2}$ \\ 1 Faculty of Applied Biological Sciences, Graduate School of Applied Biological Sciences, Gifu University, \\ 1-1 Yanagido, Gifu City, Gifu 501-1193, Japan; maya@ukwms.ac.id \\ 2 Department of Food Science and Technology, Faculty of Agricultural Engineering and Technology, \\ IPB University, Kampus IPB Dramaga, Bogor 16680, West Java, Indonesia; dedi_fardiaz@yahoo.com.sg (D.F.); \\ hanifahlioe@apps.ipb.ac.id (H.N.L.) \\ 3 Department of Food Technology, Faculty of Agricultural Technology, Widya Mandala Catholic University \\ Surabaya, Jalan Dinoyo 42-44, Surabaya 60265, East Java, Indonesia \\ 4 Department of Chemistry, Faculty of Mathematics and Natural Science, IPB University, Kampus IPB Dramaga, \\ Bogor 16680, West Java, Indonesia; imebatubara@gmail.com \\ 5 Tropical Biopharmaca Research Center IPB University, Kampus IPB Taman Kencana No 3, \\ Bogor 16128, West Java, Indonesia \\ * Correspondence: e-yanase@gifu-u.ac.jp; Tel.: +81-58-293-2914
}

Received: 4 May 2020; Accepted: 25 May 2020; Published: 27 May 2020

\begin{abstract}
Although the intake of jack bean (Canavalia ensiformis (L.) DC.), an underutilized tropical legume, can potentially decrease the risk of several chronic diseases, not much effort has been directed at profiling the polyphenolics contained therein. Hence, this work aimed to identify and quantify the dominant jack bean polyphenolics, which are believed to have antioxidant and other bioactivities. Four major compounds were detected and identified as kaempferol glycosides with three or four glycoside units. Their structures were established based on UV-visible, 1D, 2D NMR, and HR-ESI-MS analyses. Specifically, kaempferol 3-O- $\alpha$-L-rhamnopyranosyl $(1 \rightarrow 6)$ $\beta$-D-glucopyranosyl (1 $\rightarrow 2)$ - $\beta$-D-galactopyranosyl-7-O-[3-O-o-anisoyl]- $\alpha$-L-rhamnopyranoside was detected for the first time, while the other three compounds have already been described in plants other than jack bean. This new compound was found to have a higher $\alpha$-glucosidase inhibition activity compared to acarbose.
\end{abstract}

Keywords: Canavalia ensiformis; legume; jack bean; constituent profiling; flavonol glycosides; flavonoid

\section{Introduction}

Diabetes is one of the diseases whose global patient prevalence has increased every year. Persons with diabetes are predicted to increase from 463 million in 2019 to 700 million in 2045, a $51 \%$ increase, mainly from increases in low and middle income countries [1]. Type 2 diabetes accounts for the vast majority (around 90\%) of diabetes worldwide. This disease refers to the insufficient of insulin uptake of glucose in blood, causing a high blood glucose level. It can lead to complications in many parts of the body and develop some serious life-threatening health problems when not well managed.

Decreasing postprandial hyperglycemia has become one of the effective ways to manage diabetes mellitus, in particular, non-insulin-dependent diabetes mellitus (NIDDM). During carbohydrates metabolism, $\alpha$-glucosidase is the key enzyme catalyzing the final step in the digestive process as 
liberated d-glucose from dietary complex carbohydrates [2]. Inhibition of carbohydrate hydrolyzing enzymes, such as $\alpha$-glucosidase and $\alpha$-amylase, in the digestive organs retard the absorption of glucose. As the result, there are reduced postprandial plasma glucose levels and suppression of postprandial hyperglycemia [3]. However, using drugs for diabetes management may have several negative side effects for the patients, such as cardiovascular disease and morbidity $[4,5]$.

In recent years, many efforts have been made to identify effective $\alpha$-glucosidase inhibitors from natural sources in order to transiently lower the blood glucose, preventing heart disease and high blood pressure, also enhancing the antioxidant system, insulin action, and secretion [6]. this compound might be applied in development of a functional food or lead compounds for use against diabetes. Polyphenols, mainly flavonoids and phenolic acids [7], have been isolated from plants found as $\alpha$-glucosidase inhibitors. Parts of those plants are edible and are processed and consumed daily, such as fruits, vegetables, cereals, and legumes.

Legumes such as soybeans, peanuts, mung beans, and red kidney beans are major sources of dietary protein for millions of people in developing countries, including Indonesia. Jack bean (Canavalia ensiformis (L.) DC.) is one of the legume plants cultivated in Indonesia and other parts of East Asia. The high protein content of this bean makes them a promising food [8,9]. In addition, this bean is easy to cultivate due to its high adaptability to adverse conditions. On the other hand, jack bean is actually underutilized as food, although commonly used as a fertilizer and animal feed. This is because jack bean seeds contain toxic and antinutritional compounds such as concanavalin A and are therefore of limited use as human food or animal feed [10-13]. However, the content of these harmful compounds can be easily reduced by heating [10,14-16] and non-heating processes such as germination and using chemicals [15].

In addition, jack bean seeds contain saponins, flavonoids, and alkaloids [17], as well as certain polyphenols that exhibit antioxidant activity and can potentially decrease the risk of several chronic diseases $[8,18,19]$, include diabetes mellitus. Nevertheless, not much is currently known about the type and amounts of polyphenols in jack bean. In view of the above, the present work aims to identify, quantify the dominant polyphenolics in jack bean, and investigate its potency as an antidiabetic agent.

\section{Results and Discussion}

Jack bean flour was extracted with $\mathrm{MeOH}$, and the extract was subjected to reverse-phase column chromatography using sequential elution with 20,50, 80, and $100 \mathrm{vol} \%$ aqueous $\mathrm{MeOH}$ to obtain four fractions (F20, F50, F80, and F100, respectively). HPLC analysis of these fractions revealed the presence of multiple peaks in F50 and F80, which were therefore subjected to further separation (Figure 1). F50 was subjected to normal-phase column chromatography to afford $\mathbf{1}$ and $\mathbf{2}$ as major products, while F80 was subjected to reverse-phase preparative chromatography to afford 3 and 4 . The chemical structures of the isolated compounds were investigated and identified through intensive spectroscopic analyses based on 1D and 2D nuclear magnetic resonance (NMR), high-resolution electrospray ionization mass spectrometry (HR-ESI-MS), and gas chromatography mass spectrometry (GC-MS) data as follows (Figures S1-S41).

\subsection{Structure Elucidation of $\mathbf{1}-\mathbf{4}$}

According to HR-ESI-MS $\left(\mathrm{m} / \mathrm{z}\right.$ 887.2843, $\left.[\mathrm{M}+\mathrm{H}]^{+}\right), 1$ had a molecular formula of $\mathrm{C}_{39} \mathrm{H}_{50} \mathrm{O}_{23}$ (calcd. for $\left[\mathrm{C}_{39} \mathrm{H}_{51} \mathrm{O}_{23}\right]^{+}, 887.2821$ ). The corresponding ${ }^{1} \mathrm{H}$ NMR spectrum (Table 1 ) of this compound assigned a flavanol based on the exhibited signals at 6.81 and $8.00 \mathrm{ppm}$ corresponding to the four aromatic protons ( $\mathrm{AA}^{\prime} \mathrm{BB}^{\prime}$ ) of $\mathrm{B}$ ring, and signals at 6.36 and $6.63 \mathrm{ppm}$ corresponding to the two meta-aromatic protons of A ring. ${ }^{13} \mathrm{C}$ NMR (Table 1 ) and heteronuclear multiple quantum coherence spectroscopy (HMQC) data suggested the presence of 39 carbons, including one carbonyl carbon (179.52 ppm), eight non-protonated carbons, twenty-six methine carbons, one methylene carbon, and three methyl carbons. Heteronuclear multiple bond correlation spectroscopy (HMBC) analysis revealed a long-range 
correlation between the ${ }^{1} \mathrm{H}$ signal at $8.00 \mathrm{ppm}\left(\mathrm{H}-2^{\prime}\right.$ and $\left.6^{\prime}\right)$ and the ${ }^{13} \mathrm{C}$ peak at $159.22 \mathrm{ppm}(\mathrm{C} 2)$, suggesting the presence of a kaempferol skeleton.
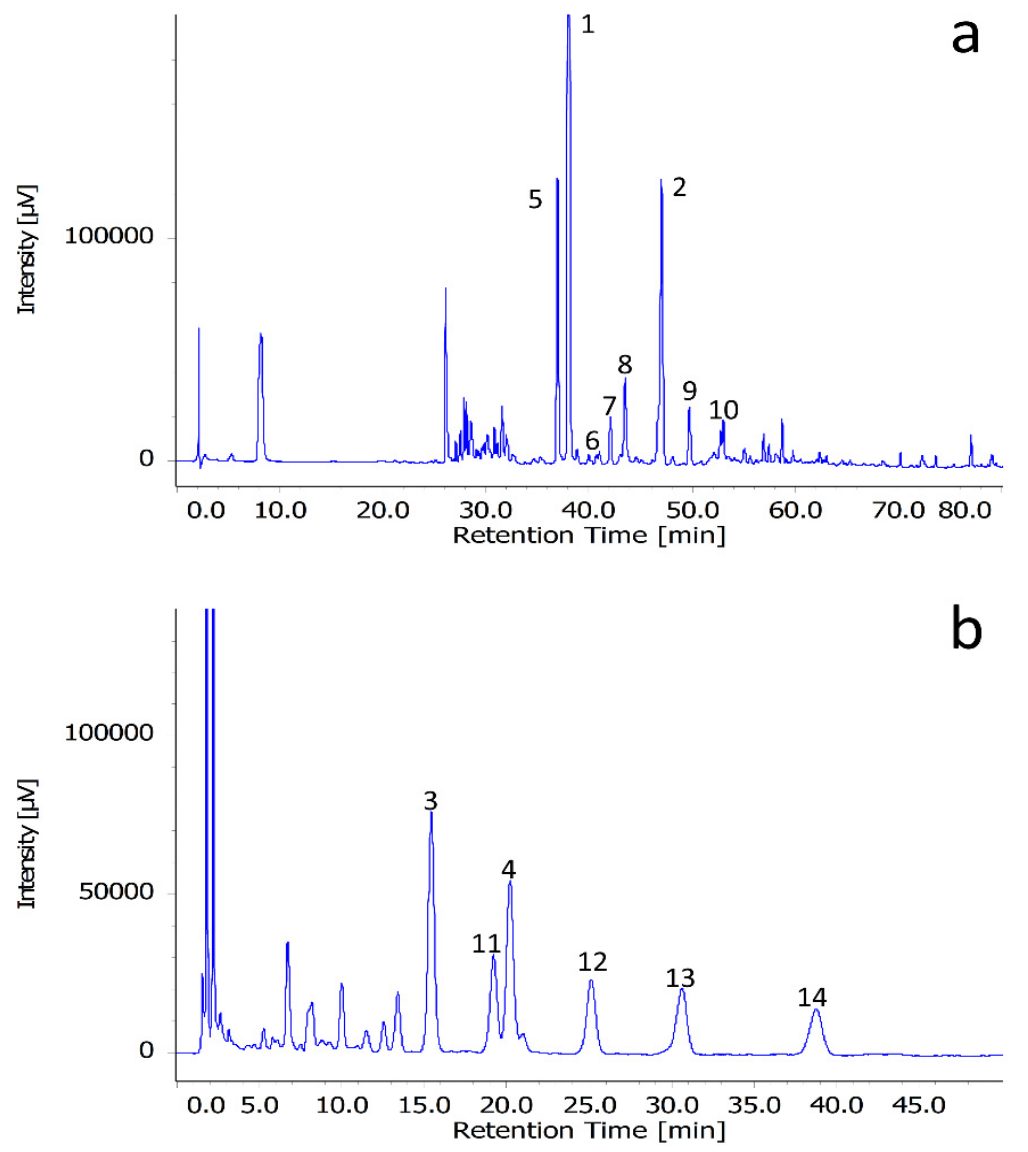

Figure 1. Chromatograms of F50 (a) and F80 (b).

Additionally, ${ }^{1} \mathrm{H}$ NMR signals at $3.21-3.93 \mathrm{ppm}$ indicated the presence of sugars. Four anomeric proton signals at 5.53, 5.12, 4.42, and $5.47 \mathrm{ppm}$ corresponded to four sugar units, three of which were $\alpha$-rhamnosyl moieties, as exemplified by the signals of the methyl group in position six at $0.88,1.07$, and $1.16 \mathrm{ppm}$. The other sugar unit was hexose and indicated as glucose because of a large coupling constant $(6.4 \mathrm{~Hz})$ detected at position C5 (3.54 ppm) of its structure.

Two rhamnose moieties were assumed to be bonded to a glucose moiety on the basis of HMBC data. The anomeric proton of rhamnose (5.12 ppm) bound to the second carbon $(77.57 \mathrm{ppm})$ of the glucose structure, while the $4.42 \mathrm{ppm}$ anomeric proton from rhamnose bound to the sixth carbon $(67.15 \mathrm{ppm})$ of the same glucose structure. HMBC cross peaks were observed between the anomeric proton of glucose and the C3 (134.72 ppm) and of rhamnose and C7 (163.40 ppm) of the kaempferol moiety.

To confirm the suggested sugar subunit structure, 1 was subjected to acid hydrolysis, and the hydrolysate was analyzed by GC-MS to reveal the presence of $\alpha$-L-rhamnose and $\beta$-D-glucose (Figure S38). Based on the combined data, 1 was identified as kaempferol 3-O- $\alpha$-L-rhamnopyranosyl $(1 \rightarrow 2)$ [ $\alpha$-L-rhamnopyranosyl $(1 \rightarrow 6)]-\beta$-D-glucopyranoside-7-O- $\alpha$-L-rhamnopyranoside (Figure 2$)$. This compound was previously isolated from Styphnolobium japonicum leaves [20] but has not been reported to be present in jack bean. All data agreed with those published for this compound previously. 
Table 1. ${ }^{1} \mathrm{H}$ and ${ }^{13} \mathrm{C}$ NMR data of compounds $\mathbf{1}-\mathbf{4}$ recorded in $\mathrm{CD}_{3} \mathrm{OD}$.

\begin{tabular}{|c|c|c|c|c|c|c|c|c|}
\hline \multirow{2}{*}{$\mathrm{C}$} & \multicolumn{2}{|c|}{$1^{a}$} & \multicolumn{2}{|c|}{$2^{a}$} & \multicolumn{2}{|c|}{$3^{a}$} & \multicolumn{2}{|l|}{$4^{b}$} \\
\hline & $\delta_{\mathrm{H}}($ mult., $J=\mathrm{Hz})$ & $\delta_{\mathrm{C}}$ & $\delta_{\mathrm{H}}($ mult., $J=\mathrm{Hz})$ & $\mathrm{d}_{\mathrm{C}}$ & $\delta_{\mathrm{H}}($ mult., $J=\mathrm{Hz})$ & $\delta_{C}$ & $\delta_{\mathrm{H}}($ mult., $J=\mathrm{Hz})$ & $\delta_{C}$ \\
\hline \multicolumn{9}{|c|}{ Aglycone } \\
\hline 2 & - & 159.22 & - & 158.64 & - & 161.79 & - & 159.22 \\
\hline 3 & - & 134.72 & - & 134.40 & - & 135.15 & - & 134.73 \\
\hline 4 & - & 179.52 & - & 179.40 & - & 179.94 & - & 179.50 \\
\hline 5 & - & 157.92 & - & 163.13 & - & 162.87 & - & 163.17 \\
\hline 6 & $6.36(\mathrm{~d}, 2.4)$ & 100.42 & $6.19(\mathrm{~d}, 2.0)$ & 99.75 & $6.55(\mathrm{~s})$ & 100.70 & $6.52(\mathrm{~s})$ & 100.30 \\
\hline 7 & - & 163.40 & - & 165.56 & - & 163.40 & - & 163.17 \\
\hline 8 & $6.63(\mathrm{~d}, 2.4)$ & 95.62 & $6.38(\mathrm{~d}, 2.0)$ & 94.64 & $6.82(\mathrm{~s})$ & 95.91 & $6.78(\mathrm{~s})$ & 95.66 \\
\hline 9 & - & 162.90 & - & 158.40 & - & 158.00 & - & 157.95 \\
\hline 10 & - & 107.50 & - & 105.90 & - & 107.30 & - & 107.68 \\
\hline $1^{\prime}$ & & 122.80 & & 123.00 & & 122.40 & & 122.80 \\
\hline $2^{\prime}, 6^{\prime}$ & $8.00(\mathrm{~d}, 8.8)$ & 132.33 & $8.06(\mathrm{~d}, 8.8)$ & 132.30 & $8.13(\mathrm{~d}, 8.8)$ & 132.65 & $8.11(\mathrm{~d}, 8.6)$ & 132.34 \\
\hline $3^{\prime}, 5^{\prime}$ & $6.81(\mathrm{~d}, 8.8)$ & 116.25 & $6.90(\mathrm{~d}, 8.8)$ & 116.20 & $6.93(\mathrm{~d}, 8.8)$ & 116.33 & $6.92(\mathrm{~d}, 8.2)$ & 116.23 \\
\hline $4^{\prime}$ & - & 161.50 & - & 161.30 & - & 159.64 & - & 161.40 \\
\hline \multicolumn{9}{|c|}{ 3-O-Glc/3-O-Gal ${ }^{\mathrm{c}}$} \\
\hline 1 & $5.53(\mathrm{~d}, 8.0)$ & 100.82 & $5.60(\mathrm{~d}, 8.0)$ & 100.83 & $5.28(\mathrm{~d}, 7.0)$ & 101.64 & $5.63(\mathrm{br} \mathrm{s})$ & 100.79 \\
\hline 2 & $3.84(\mathrm{br} \mathrm{s})$ & 77.57 & $3.92(\mathrm{dd}, 9.6,8.0)$ & 77.54 & $4.07(\mathrm{dd}, 7.8,9.4)$ & 80.14 & $3.95(\mathrm{t}, 8.4)$ & 77.58 \\
\hline 3 & $3.61(\mathrm{dd}, 3.2,9.6)$ & 75.69 & $3.69(\mathrm{dd}, 3.2,9.6)$ & 75.70 & $3.73(\mathrm{~m})$ & 74.74 & 3.70 (br s) & 75.58 \\
\hline 4 & $3.68(\mathrm{~d}, 3.2)$ & 70.67 & $3.76(\mathrm{~d}, 3.2)$ & 70.68 & $3.81(\mathrm{~m})$ & 70.92 & $3.78(\mathrm{~d}, 3.0)$ & 70.63 \\
\hline 5 & $3.54(\mathrm{t}, 6.4)$ & 75.34 & $3.63(\mathrm{t}, 6.4)$ & 75.29 & 3.35 (br s) & 78.20 & $3.48(\mathrm{br} \mathrm{s})$ & 72.34 \\
\hline 6 & $3.36(\mathrm{~m}) ; 3.68(\mathrm{~m})$ & 67.15 & $3.49(\mathrm{~m}) ; 3.72(\mathrm{~m})$ & 67.11 & $3.70(\mathrm{~m})$ & 62.56 & $3.65(\mathrm{~m}), 3.70(\mathrm{~m})$ & 67.14 \\
\hline \multicolumn{9}{|c|}{$2^{\prime \prime}-\mathrm{O}-\mathrm{Rha} / 2^{\prime \prime}-\mathrm{O}-\mathrm{Gl} \mathrm{c}^{\mathrm{d}}$} \\
\hline 1 & $5.12(\mathrm{~s})$ & 102.59 & 5.21 (br s) & 102.60 & $4.77(\mathrm{~d}, 7.2)$ & 104.80 & $5.25(\mathrm{~s})$ & 102.54 \\
\hline 2 & 3.91 (br s) & 71.68 & $4.00(\mathrm{~m})$ & 72.40 & $3.41(\mathrm{~m})$ & 71.23 & $4.01(\mathrm{br} \mathrm{s})$ & 72.34 \\
\hline 3 & $3.69(\mathrm{dd}, 3.2,9.6)$ & 72.37 & $3.80(\mathrm{dd}, 3.2,9.6)$ & 72.44 & $3.42(\mathrm{~m})$ & 77.85 & $3.82(\mathrm{br} \mathrm{s})$ & 72.01 \\
\hline 4 & $3,25(t, 9.6)$ & 74.02 & $3.34(t, 5.6)$ & 74.06 & $3.40(\mathrm{~d}, 2.4)$ & 75.56 & $3.40(\mathrm{~m})$ & 74.03 \\
\hline 5 & $3.95(\mathrm{dd}, 6.4,9.6)$ & 69.83 & $4.06(\mathrm{~m})$ & 69.81 & $3.61(t, 6.0)$ & 75.26 & $3.50(\mathrm{~m})$ & 69.79 \\
\hline 6 & $0.88(\mathrm{~d}, 6.4)$ & 17.54 & $0.97(\mathrm{~d}, 5.6)$ & 17.53 & $3.65(\mathrm{br} \mathrm{s}) ; 3.40(\mathrm{~m})$ & 67.21 & $1.17(\mathrm{~d}, 6.0)$ & 17.94 \\
\hline \multicolumn{9}{|c|}{$6^{\prime \prime}-$ O-Rha/1'1"-O-Rha } \\
\hline 1 & $4.42(\mathrm{~s})$ & 101.80 & $4.52(\mathrm{~s})$ & 101.86 & 4.51 (br s) & 101.83 & $4.51(\mathrm{br} \mathrm{s})$ & 101.78 \\
\hline 2 & 3.45 (br s) & 71.68 & 3.56 (br s) & 72.07 & 3.55 (br s) & 72.03 & $3.55(\mathrm{br} \mathrm{s})$ & 72.25 \\
\hline 3 & $3.40(\mathrm{~m})$ & 72.23 & $3.51(\mathrm{~m})$ & 72.27 & $3.48(\mathrm{dd}, 9.6,4.0)$ & 72.26 & $3.46(\mathrm{~d}, 5.4)$ & 67.14 \\
\hline 4 & $3.21(\mathrm{~m})$ & 73.86 & $3.27(\mathrm{~m})$ & 73.85 & $3.27(t, 9.6)$ & 73.86 & 3.29 (br s) & 73.86 \\
\hline 5 & $3.41(\mathrm{~m})$ & 69.66 & $3.53(\mathrm{~m})$ & 69.68 & $3.51(\mathrm{~m})$ & 69.67 & $4.06(\mathrm{~m})$ & 69.63 \\
\hline 6 & $1.07(\mathrm{~d}, 6.4)$ & 17.95 & $1.17(\mathrm{~d}, 5.6)$ & 17.94 & $1.17(\mathrm{~d}, 5.6)$ & 17.94 & $0.99(\mathrm{~d}, 6.0)$ & 17.54 \\
\hline
\end{tabular}


Table 1. Cont

\begin{tabular}{|c|c|c|c|c|c|c|c|c|}
\hline \multirow{2}{*}{$\mathrm{C}$} & \multicolumn{2}{|c|}{$1^{\mathrm{a}}$} & \multicolumn{2}{|c|}{$2^{a}$} & \multicolumn{2}{|c|}{$3^{a}$} & \multicolumn{2}{|l|}{$4^{b}$} \\
\hline & $\delta_{\mathrm{H}}($ mult., $J=\mathrm{Hz})$ & $\delta_{\mathrm{C}}$ & $\delta_{\mathrm{H}}($ mult., $J=\mathrm{Hz})$ & $\mathrm{d}_{\mathrm{C}}$ & $\delta_{\mathrm{H}}($ mult., $J=\mathrm{Hz})$ & $\delta_{C}$ & $\delta_{\mathrm{H}}($ mult., $J=\mathrm{Hz})$ & $\delta_{C}$ \\
\hline \multicolumn{9}{|l|}{ 7-O-Rha } \\
\hline 1 & $5.47(\mathrm{~s})$ & 99.87 & - & - & $5.63(\mathrm{~s})$ & 99.82 & $5.62(\mathrm{~s})$ & 99.81 \\
\hline 2 & 3.93 (br s) & 71.68 & - & - & 4.35 (br s) & 69.50 & 4.35 (br s) & 69.52 \\
\hline 3 & $3.73(\mathrm{dd}, 3.2,9.6)$ & 72.04 & - & - & $5.34(\mathrm{dd}, 9.6,3.2)$ & 75.42 & $5.35(\mathrm{dd}, 9.0,3.6)$ & 75.62 \\
\hline 4 & 3.39 (br s) & 73.59 & - & - & $3.84(\mathrm{t}, 9.6)$ & 70.92 & 3.81 (br s) & 70.91 \\
\hline 5 & $3.51(\mathrm{dd}, 5.6,9.6)$ & 71.24 & - & - & $3.79(\mathrm{~m})$ & 71.51 & $3.80(\mathrm{~m})$ & 71.45 \\
\hline 6 & $1.16(\mathrm{~d}, 5.6)$ & 18.10 & - & - & $1.33($ d. 6.4$)$ & 18.15 & $1.33(\mathrm{~d}, 6.0)$ & 18.14 \\
\hline \multicolumn{9}{|l|}{ Anis } \\
\hline$-1^{\prime}$ & - & - & - & - & - & 120.96 & - & 121.14 \\
\hline$-2^{\prime}$ & - & - & - & - & - & 160.81 & - & 160.76 \\
\hline$-3^{\prime}$ & - & - & - & - & $7.13(\mathrm{~d}, 8.8)$ & 113.37 & $7.13(\mathrm{~d}, 8.4)$ & 113.37 \\
\hline$-4^{\prime}$ & - & - & - & - & $7.55(t, 7.2)$ & 136.15 & $7.55(t, 7.8)$ & 135.19 \\
\hline$-5^{\prime}$ & - & - & - & - & $7.03(\mathrm{t}, 8.0)$ & 121.15 & $7.03(\mathrm{t}, 7.8)$ & 121.01 \\
\hline$-6^{\prime}$ & - & - & - & - & $8.00(\mathrm{~d}, 6.4)$ & 132.91 & $7.96(\mathrm{~d}, 7.8)$ & 131.48 \\
\hline$-\mathrm{OCH}_{3}$ & - & - & - & - & $3.90(\mathrm{~s})$ & 56.43 & $3.90(\mathrm{~s})$ & 56.45 \\
\hline$-\mathrm{CO}$ & - & - & - & - & - & 167.38 & - & 167.37 \\
\hline
\end{tabular}

${ }^{\mathrm{a}}$ Determined by 800-MHz NMR spectroscopy, ${ }^{\mathrm{b}}$ Determined by 600-MHz NMR spectroscopy, ${ }^{\mathrm{c}}$ Glc in $\mathbf{1}$ and 2; Gal in $\mathbf{3}$ and $4,{ }^{\mathrm{d}}$ Rha in $\mathbf{1 , 2}$, and 4; Glc in $\mathbf{3}$ 

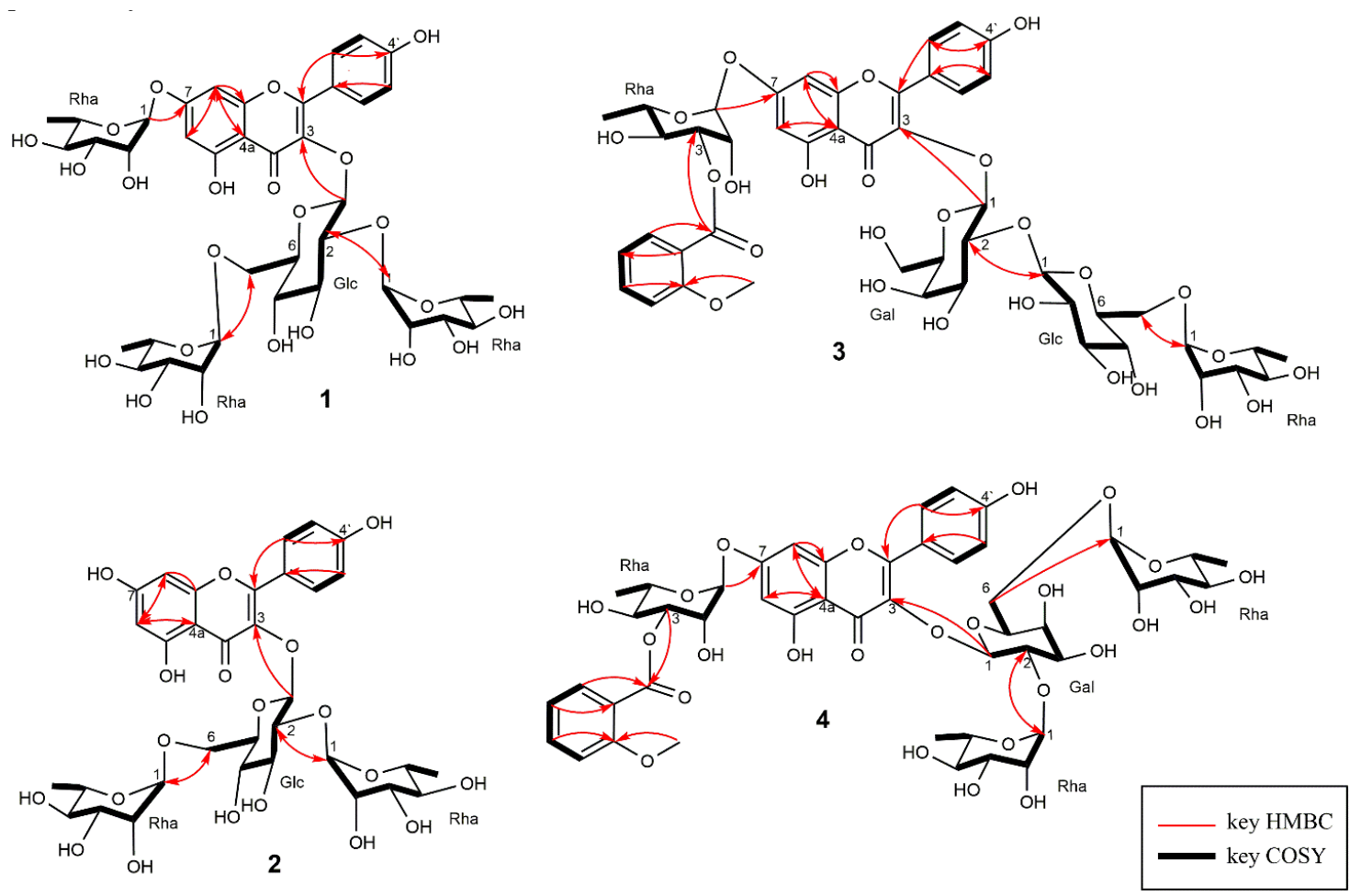

Figure 2. Chemical structures of compounds 1-4 isolated from Canavalia ensiformis. HMBC (heteronuclear multiple bond correlation spectroscopy), COSY (homonuclear correlation spectroscopy).

Based on HR-ESI-MS data $\left(\mathrm{m} / \mathrm{z} 741.2214,[\mathrm{M}+\mathrm{H}]^{+}\right), 2$ was assigned the molecular formula of $\mathrm{C}_{33} \mathrm{H}_{40} \mathrm{O}_{19}$ (calcd. for $\left[\mathrm{C}_{33} \mathrm{H}_{41} \mathrm{O}_{19}\right]^{+}, 741.2242$ ), and the corresponding ${ }^{1} \mathrm{H}$ and ${ }^{13} \mathrm{C}$ NMR data suggested the presence of a kaempferol skeleton as the aglycone. The signals of three anomeric protons at $4.52,5.21$, and $5.60 \mathrm{ppm}$ suggested the presence of three sugar units, while resonances at 0.97 and $1.17 \mathrm{ppm}$ were assigned to methyl in position six of rhamnose moieties. Taking into consideration the values of coupling constants, the sugar units were identified as $\alpha$-rhamnose and $\beta$-glucose. HMBC cross peaks were observed between the anomeric proton of glucose and C-3 position of the kaempferol moiety, and GC-MS analysis confirmed the presence of L-rhamnose and D-glucose units (Figure S39). Thus, 2 was identified as kaempferol 3-O-(2,6-di- $\alpha$-L-rhamnopyranosyl)$\beta$-D-glucopyranoside (Figure 2), which has already been isolated from petals of Clitoria ternatea [21].

Based on HR ESI-MS data $\left(\mathrm{m} / z\right.$ 1037.3076 [M + H] $\left.{ }^{+}\right), 3$ was assigned the formula of $\mathrm{C}_{47} \mathrm{H}_{56} \mathrm{O}_{26}$ (calcd. for $\left[\mathrm{C}_{47} \mathrm{H}_{57} \mathrm{O}_{26}\right]^{+}, 1037.3138$ ) and was concluded to have the same aglycone (kaempferol) as 1 and 2. ${ }^{1} \mathrm{H}$ NMR and homonuclear correlation spectroscopy (COSY) data suggested the presence of an aromatic moiety other than that of kaempferol, which was identified as anisoyl on the basis of ${ }^{13} \mathrm{C}$ NMR, HMQC, and HMBC data. Four sugar moieties were identified based on the signals of four anomeric protons at 5.63,4.77, 4.51, and $5.63 \mathrm{ppm}$. Two methyl carbons and ${ }^{1} \mathrm{H}$ signals at 1.17 and $1.33 \mathrm{ppm}$ were indicative of the existence of rhamnose, while the signals of two methylene carbons referred to position six of each hexose structure. The other two sugar units were presumed to be galactose and glucose by the coupling constant at $C 5$ position. HMBC cross peaks between the carbonyl carbon (167.38 ppm) and the proton signal at $5.34 \mathrm{ppm}$ showed the presence of an anisoyl group bonded to the $\mathrm{C} 3$ position of rhamnose. Moreover, HMBC cross peaks also allowed one to deduce the connection sequence of two hexose moieties and rhamnose (terminal position). Anomeric proton of rhamnose (4.51 ppm) was connected to C6 (62.56 ppm) in the glucose structure, while its anomeric proton $(4.77 \mathrm{ppm})$ was connected to $\mathrm{C} 2(80.14 \mathrm{ppm})$ in the galactose structure so that those three sugars were connected sequentially. Galactose was bound to the C3 position (135.15 ppm) of kaempferol through its anomeric proton (5.28 ppm). 
GC-MS analysis confirmed the presence of L-rhamnose, D-galactose, and D-glucose (Figure S40). Thus, 3 was identified as kaempferol 3-O- $\alpha$-L-rhamnopyranosyl $(1 \rightarrow 6)-\beta$-D-glucopyranosyl $(1 \rightarrow 2)-\beta$-D-galactopyranosyl-7-O-[3-O-o-anisoyl]- $\alpha$-L-rhamnopyranoside (Figure 2 ). Compound 3 was found to be similar to gladiatoside $A_{2}$, which was previously isolated from sword bean (Canavalia gladiata). Those two compounds had the same mass number and contained the same type of four glycoside units and one anisoyl unit [22].

The fundamental differences between these two compounds were in the bonding position between L-rhamnose, D-glucose, and D-galactose that are attached in the C3 position of the kaempferol. In the gladiatoside $A_{2}$, galactose was connected to glucose through a $(1 \rightarrow 2)$ linkage and to rhamnose by a $(1 \rightarrow 6)$ linkage. Meanwhile in 3 , L-rhamnose was connected to glucose by a $(1 \rightarrow 6)$ linkage and D-glucose connected by a $(1 \rightarrow 2)$ linkage to D-galactose unit and formed a linear structure of trisaccharide. This sequence connection of galactose, glucose, and rhamnose made 3 different to gladiatoside $\mathrm{A}_{2}$ and found it as a novel compound.

Based on HR-ESI-MS data $\left(m / z 1021.3170[\mathrm{M}+\mathrm{H}]^{+}\right)$, 4 was assigned the formula of $\mathrm{C}_{47} \mathrm{H}_{56} \mathrm{O}_{26}$ (calcd. for $\left[\mathrm{C}_{47} \mathrm{H}_{57} \mathrm{O}_{25}\right]^{+}, 1021.3189$ ), featuring kaempferol as the aglycone, four glycoside moieties, and one anisoyl unit, similarly to 3 . The four sugar units were identified based on the four anomeric proton signals at 5.63, 5.25, 4.51, and 5.62. Proton signals at 1.17, 0.99, and $1.33 \mathrm{ppm}$ corresponded to the 6-position of $\alpha$-rhamnose moieties. GC-MS analysis confirmed the presence of L-rhamnose and $D$-galactose units (Figure S41). Thus, 4 was identified as kaempferol 3-O-(2,6-di- $\alpha$-L-rhamnopyranosyl)- $\beta$-D-galactopyranoside-7-O-[3-O-o-anisoyl]- $\alpha$-L-rhamnopyranoside (Figure 2), which has previously been isolated as gladiatoside $B_{2}$ from sword bean (Canavalia gladiata) [22].

\subsection{UPLC-ESI-MS/MS Analysis}

The fragmentation patterns (in particular, the neutral loss) of each pseudo molecular ion were used to identify the type and number of sugar residues (Figure S21-S34). Fragments of 1 (Table 2, Figure S21) with $\mathrm{m} / z 741.2214$ and 595.1542 corresponded to neutral losses of 146 and 292 Da from the pseudomolecular ion with $m / z$ 887.28434 $\left([\mathrm{M}+\mathrm{H}]^{+}\right)$, i.e., reflected the loss of two rhamnosyl residues. In addition, the fragment at $m / z 433.0958$ corresponded to a neutral loss of $454 \mathrm{Da}$, i.e., to the loss of two rhamnose and glucose units. This data suggested that two rhamnose units bonded to the glucose unit attached to the $\mathrm{C} 3$ position. It was because fragmentation occurs most easily in the $\mathrm{C} 3$ position in the positive mode. [23,24]. The fact that the relative abundance of ${ }^{3} Y_{1}{ }^{+}(\mathrm{m} / z$ 595.1542) exceeded that of ${ }^{3} \mathrm{Y}_{2}{ }^{+}(\mathrm{m} / \mathrm{z} 741.2214)$ suggested that one rhamnose was $(1 \rightarrow 2)$ linked to the glucose, while the other rhamnose was connected in a $(1 \rightarrow 6)$ linkage [23-25].

Table 2. MS/MS fragment ions of compounds 1-4.

\begin{tabular}{|c|c|c|c|c|c|c|c|c|c|}
\hline \multirow{2}{*}{ Compound } & \multicolumn{9}{|c|}{ Fragment Ions ${ }^{a}$} \\
\hline & ${ }^{3} Y_{2}$ & ${ }^{3} Y_{1}$ & ${ }^{3} Y_{0}$ & ${ }^{3} Z_{2}$ & ${ }^{3} \mathrm{Z}_{1}$ & ${ }^{3} Y_{0}{ }^{7} Y_{2}$ & ${ }^{3} Y_{0}{ }^{7} Y_{1}$ & ${ }^{3} Y_{0}{ }^{7} Y_{0}$ & {$[A+R]^{+b}$} \\
\hline 1 & 741.2214 & 595.1542 & 433.0958 & n.d ${ }^{c}$ & 579.1572 & n.d & n.d & 287.0376 & - \\
\hline 2 & 595.1542 & 449.1033 & 287.0376 & n.d & 433.0958 & - & - & - & - \\
\hline 3 & 891.2531 & 729.1957 & 567.1334 & 875.2322 & n.d & n.d & 433.1136 & 287.0576 & 281.1014 \\
\hline 4 & 875.2546 & 729.2129 & 567.1486 & n.d & 713.1918 & 433.1136 & n.d & 287.0576 & 281.1014 \\
\hline
\end{tabular}

Fragmentation in the negative mode explained the presence of one rhamnose moiety attached to C7 position of kaempferol skeleton as showed by the neutral loss of 146 Da between pseudomolecular ion with $\mathrm{m} / \mathrm{z} 885.2556[\mathrm{M}-\mathrm{H}]^{-}$and fragment ion of $\mathrm{m} / \mathrm{z} 739.6731$. It was reported that the glycoside in the $C 7$ position is easy to be fragmented in negative mode [26,27]. Therefore, $\mathbf{1}$ contained one glucose unit and three rhamnose units, two of which were bound to the glucose unit. The above data agreed with the structure put forward based on NMR data (Figures 2 and 3). 


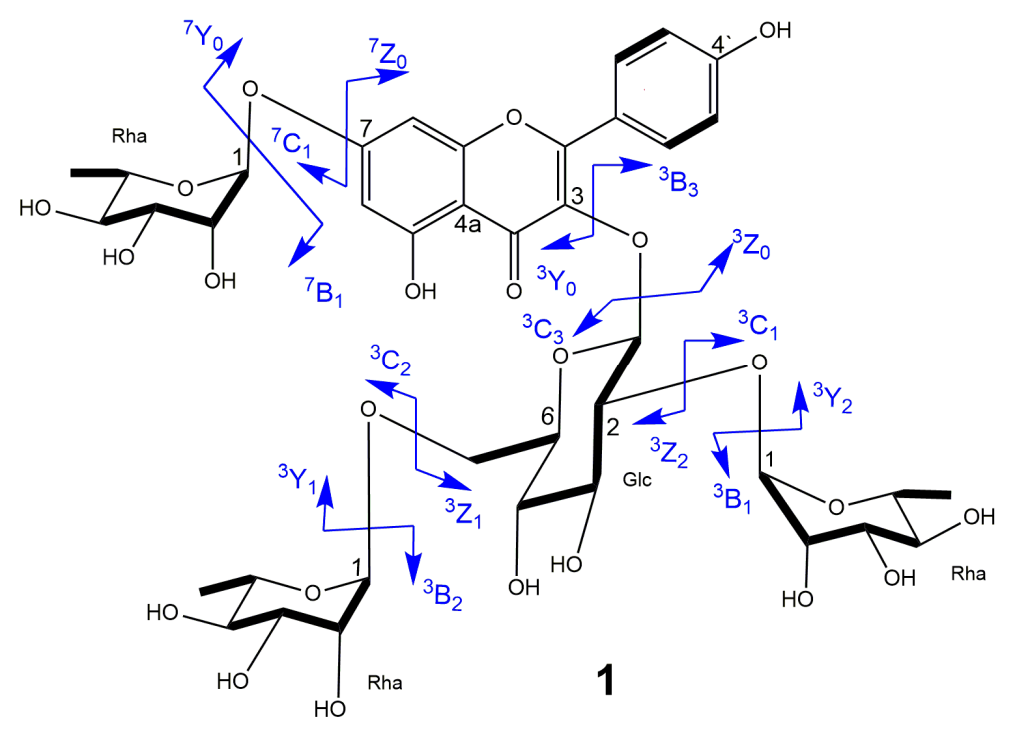

Figure 3. Fragmentation patterns of compound 1.

Similar fragmentation patterns were observed for 2-4. In addition, fragment ions with $\mathrm{m} / z 135$ and 281 for 3 and 4 supported the presence of a rhamnose unit with an anisoyl group (Figures S23-S24). Thus, MS/MS data (Table 2) supported the structure proposed based on NMR data.

The major constituents of F50 and F80, isolated by column chromatography and preparative HPLC, were identified as 1 and 2 (F50) and 3 and 4 (F80). In addition to the four dominant compounds, F50 and F80 contained 10 other compounds at levels that did not allow the isolation of sufficient quantities for NMR analysis (1D and 2D). Compounds 5-10, identified in F50, and compounds 11-14, obtained from F80, exhibited similar UV-vis spectral patterns with compounds 1-4 and were therefore presumed to be kaempferol derivatives. Therefore, further identification was carried out using MS/MS analysis. The fragment ion at $m / z 287$ indicated that 5-14 contained kaempferol as the aglycone (Table 3, Figures S25-S34).

The glycoside compositions of 5-14 were identified as described previously, with MS/MS data for each compound presented in Figures S25-S34 and the relative mass number (indicated as $[\mathrm{M}+\mathrm{H}]^{+}$), aglycone, and glycan composition of each compound listed in Table 3. Compounds 11 and 13 were isomers of 3 , while 12 and 14 were isomers of 4 and were identified as gladiatosides $B_{1}$ and $B_{3}$, respectively [22].

\subsection{Quantitation of Kaempferol Content in Methanolic Jack Bean Extract}

The kaempferol glycosides content in jack bean extract was determined from HPLC peak areas (Table 3). The overall kaempferol glycoside content (calculated as the total of fourteen compounds) in jack bean flour was $5.57 \mathrm{mg} / 100 \mathrm{~g}$ and compounds 1-4 composed $2.29 \mathrm{mg} / 100 \mathrm{~g}(41.05 \%), 0.67 \mathrm{mg} / 100 \mathrm{~g}$ (11.94\%), $0.49 \mathrm{mg} / 100 \mathrm{~g}(8.81 \%)$, and $0.39 \mathrm{mg} / 100 \mathrm{~g}(7.03 \%)$. This data explained that this bean was a good source of $\mathbf{1}$ and in accordance with the highest isolation amount obtained in this research. Furthermore, $52.75 \%$ of total kaempferol was kaempferol tetraglycosides, while kaempferol triglycosides was $17.71 \%$. 
Table 3. Characterization of compounds 1-14.

\begin{tabular}{|c|c|c|c|c|c|c|c|c|c|}
\hline \multirow{2}{*}{ Compound } & \multirow{2}{*}{$\begin{array}{c}\text { Content } \\
(\mathrm{mg} / 100 \mathrm{~g} \text { dry wt.) }\end{array}$} & \multirow{2}{*}{ Formula } & \multicolumn{3}{|c|}{$[\mathrm{M}+\mathrm{H}]+$} & \multirow{2}{*}{ Aglycone ${ }^{b}$} & \multicolumn{2}{|c|}{ Derivatives $^{c}$} & \multirow{2}{*}{ Detection } \\
\hline & & & Calculated Mass & Exact Mass & Mass Error(ppm) & & Glycans & Other & \\
\hline 1 & $2.2862 \pm 0.0745$ & $\mathrm{C}_{39} \mathrm{H}_{50} \mathrm{O}_{23}$ & 887.2821 & 887.2843 & 2.4795 & $\mathrm{~K}$ & Rha, Rha, Rha, Hex & & MS, NMR \\
\hline 2 & $0.6651 \pm 0.0205$ & $\mathrm{C}_{33} \mathrm{H}_{40} \mathrm{O}_{19}$ & 741.2242 & 741.2214 & -3.7775 & K & Rha, Rha, Hex & & MS, NMR \\
\hline 3 & $0.4906 \pm 0.0176$ & $\mathrm{C}_{47} \mathrm{H}_{56} \mathrm{O}_{26}$ & 1037.3138 & 1037.3076 & -5.9770 & K & Rha, Rha, Hex, Hex & Anis & MS, NMR \\
\hline 4 & $0.3916 \pm 0.0134$ & $\mathrm{C}_{47} \mathrm{H}_{56} \mathrm{O}_{25}$ & 1021.3189 & 1021.3170 & -1.8603 & K & Rha, Rha, Rha, Hex & Anis & MS, NMR \\
\hline 5 & $0.5743 \pm 0.0185$ & $\mathrm{C}_{39} \mathrm{H}_{50} \mathrm{O}_{24}$ & 903.2770 & 903.2747 & -2.5463 & $\mathrm{~K}$ & Rha, Rha, Hex, Hex & & MS \\
\hline 6 & $0.0778 \pm 0.0033$ & $\mathrm{C}_{38} \mathrm{H}_{48} \mathrm{O}_{23}$ & 873.2665 & 873.2609 & -6.4127 & K & Rha, Rha, Hex, Xyl & & MS \\
\hline 7 & $0.1987 \pm 0.0072$ & $\mathrm{C}_{33} \mathrm{H}_{40} \mathrm{O}_{20}$ & 757.2191 & 757.2161 & -3.9617 & K & Rha, Hex, Hex & & MS \\
\hline 8 & $0.0139 \pm 0.0031$ & $\mathrm{C}_{33} \mathrm{H}_{40} \mathrm{O}_{19}$ & 741.2242 & 741.2214 & -3.7775 & K & Rha, Rha, Hex & & MS \\
\hline 10 & $0.0520 \pm 0.0015$ & $\mathrm{C}_{27} \mathrm{H}_{30} \mathrm{O}_{15}$ & 595.1663 & 595.1622 & -6.8888 & K & Rha, Hex & & MS \\
\hline 11 & $0.3045 \pm 0.0162$ & $\mathrm{C}_{47} \mathrm{H}_{56} \mathrm{O}_{26}$ & 1037.3138 & 1037.3076 & -5.9770 & K & Rha, Rha, Hex, Hex & Anis & MS \\
\hline 12 & $0.2475 \pm 0.0105$ & $\mathrm{C}_{47} \mathrm{H}_{56} \mathrm{O}_{25}$ & 1021.3189 & 1021.3170 & -1.8603 & $\mathrm{~K}$ & Rha, Rha, Rha, Hex & Anis & MS \\
\hline 13 & $0.0866 \pm 0.0037$ & $\mathrm{C}_{47} \mathrm{H}_{56} \mathrm{O}_{26}$ & 1037.3138 & 1037.3076 & -5.9770 & K & Rha, Rha, Hex, Hex, & Anis & MS \\
\hline 14 & $0.0722 \pm 0.0030$ & $\mathrm{C}_{47} \mathrm{H}_{56} \mathrm{O}_{25}$ & 1021.3189 & 1021.3170 & -1.8603 & K & Rha, Rha, Rha, Hex & Anis & MS \\
\hline
\end{tabular}

${ }^{\mathrm{a}}$ Values were expressed as mean $\pm \mathrm{SD}(\mathrm{n}=4),{ }^{\mathrm{b}} \mathrm{K}=$ kaempferol, ${ }^{\mathrm{c}} \mathrm{Rha}=$ rhamnosyl; Gal = galactosyl; Glu = glucosyl; Hex = hexose, $\mathrm{Xyl}=\mathrm{xylosyl} ;$ Anis $=$ anisoyl 


\subsection{In Vitro $\alpha$-Glucosidase Inhibition Activity}

Inhibitory activity of $\alpha$-glucosidase is one of the useful parameters to show the potential of compounds 1-4 for preventing diabetes. This enzyme plays a main role in hydrolyzing sugar compounds into monomers that can be easily absorbed in the small intestine. Inhibition activity of the $\alpha$-glucosidase enzyme by the compounds $\mathbf{1 - 4}$ showed in Table 4.

Table 4. In vitro $\alpha$-glucosidase inhibition activity of compounds $\mathbf{1 - 4}$.

\begin{tabular}{cc}
\hline Sample $^{*}$ & Inhibition Activity $(\%) * *$ \\
\hline F20 & trace ${ }^{* * *}$ \\
F50 & $24.91 \pm 0.84^{\mathrm{a}}$ \\
F80 & $51.34 \pm 1.23^{\mathrm{d}}$ \\
F100 & trace \\
Compound 1 & $30.96 \pm 1.62^{\mathrm{b}}$ \\
Compound 2 & $39.54 \pm 0.69^{\mathrm{c}}$ \\
Compound 3 & $90.07 \pm 1.60^{\mathrm{g}}$ \\
Compound 4 & $77.06 \pm 0.79^{\mathrm{f}}$ \\
Acarbose & $71.71 \pm 0.08^{\mathrm{e}}$
\end{tabular}

\footnotetext{
* purity of 1-4 were depicted at Figures S42-S43, ${ }^{* *}$ value expressed as mean \pm SD $(\mathrm{n}=3)$. value followed with different letter showed statistical significant different at $p<0.05$ (Tukey's test), ${ }^{* * *}$ inhibition activity was not detected in the analysis sample concentration $(1 \mathrm{mg} / \mathrm{mL})$.
}

Moderate inhibitory activity of glucosidase was observed in the subfractions F50 and F80. Compounds 1-4, obtained by further purification, exhibited higher inhibition activity and were significantly different $(p<0.05)$ than before separation. This result suggested that compounds 1-4 were one of the important active components of each sub fraction. F80 had higher inhibition activity than F50 (Table 4). Compounds 1 and 2, obtained from F50, had low inhibitory activity compared to acarbose. It has been reported that glycosylation of flavonoids lowered the inhibitory activity through $\alpha$-glucosidase [28], and our result is in agreement with it. The bigger number of glycosides attached caused a lowering of the inhibition effect [29].

Inhibition activity of compound 3 and 4, obtained from F80. were significantly higher than acarbose, 1 and 2. Although 3 and 4 were kaempferol glycosides, the presence of anisoyl groups attached to rhamnose moiety at position C7 distinguished these two compounds with $\mathbf{1}$ and 2 . The presence of anisoyl groups made stronger the inhibition activity of $\alpha$-glucosidase. As anisoyl group was thought to influence the high activity of $\alpha$-glucosidase inhibition activity (Table 4), all kaempferol glycosides with anisoyl group may have similar ability to inhibit $\alpha$-glucosidase activity. As described in Section 2.3, those compounds composed $28.60 \%(1.59 \mathrm{mg} / 100 \mathrm{~g})$ of kaempferol glycosides content in jack bean. That described that this bean has potency as an ingredient for functional food. Compound 3 had higher inhibitory activity than 4 , although the number of sugar moiety was same. This result suggested that the difference of binding pattern of sugar moiety might be influenced by the inhibition activity.

\section{Materials and Methods}

\subsection{Plant Materials}

Jack beans (C. ensiformis (L.) DC.) were purchased from a local farmer located in Temanggung, Central Java. Broken, molded, sprouted, and damaged beans were removed before shipping to the laboratory. This bean had been identified by the Research Center for Biology, Indonesian Institute of Science No. 1761/IPH.1.01/If.07/VII/2017 and stored at Tropical Biofarmaca Research Center with a voucher specimen No. BMK0461012020. The beans were further peeled, ground, and sieved through 100 -mesh sieves to prepare jack bean flour that was stored at $-30{ }^{\circ} \mathrm{C}$ prior to analysis. 


\subsection{Reagents and Standards}

For extraction and isolation, n-hexane and methanol were purchased from Kanto Chemicals (Osaka, Japan) and Kieselgel $60 \mathrm{~F}_{254}$ purchased from Merck (Darmstadt, Germany) used for thin-layer chromatography (TLC). Deuteromethanol ( $\mathrm{CD}_{3} \mathrm{OD}$ ) (Kanto Chemical, Osaka, Japan) was used for preparing NMR samples. The mobile phase used for HPLC and UPLC were acetonitrile (Kanto Chemical, Osaka, Japan) and formic acid (FUJIFILM Wako Pure Chemical, Japan). L-cysteine methyl ester hydrochloride and N, O-bis (trimethylsilyl) trifluoroacetamide (Tokyo Chemical Industry, Tokyo, Japan) and pyridine (Nacalai Tesque, Japan) were used for acid hydrolysis of GC-MS samples. Methanol purchased from Nacalai Tesque used for polarimeter, UV and quantification analysis. Kaempferol as standard for quantification was purchased from Tokyo Chemical Industry (Japan) For IR analysis, $\mathrm{KBr}$ was purchased from FUJIFILM Wako Pure Chemical. For the $\alpha$-glucosidase inhibitory activity assay, $\alpha$-glucosidase from Saccharomyces cerevisiae was purchased from Sigma Aldrich (Germany). Acarbose hydrate, as the positive control, was obtained from Tokyo Chemical Industry (Tokyo, Japan). Phosphate buffer was prepared by mixing dipotassium hydrogen phosphate and potassium dihydrogen phosphate purchased from FUJIFILM Wako Pure Chemical. Dimethyl sulfoxide, sodium chloride, and sodium carbonate were purchased from Nacalai Tesque.

\subsection{Extraction and Isolation}

Jack bean flour (1000 g) was extracted with $5 \mathrm{~L}$ hexane $\left(25^{\circ} \mathrm{C}, 24 \mathrm{~h}\right)$ using a shaker to remove fats, and the solid residue was isolated by filtration and dried to obtain fat-free bean flour. This flour was then extracted with methanol $\left(3 \times 5 \mathrm{~L}, 25^{\circ} \mathrm{C}, 2 \mathrm{~h}\right)$, and the extract was isolated by filtration and concentrated under reduced pressure. The residue was suspended in $\mathrm{H}_{2} \mathrm{O}(200 \mathrm{~mL})$ and chromatographed on a Daion HP-20SS (Mitsubishi Chemical Corporation, Tokyo, Japan) column. Elution was started with $\mathrm{H}_{2} \mathrm{O}$ to separate sugars, starch, and proteins, and was continued using progressively increasing levels of $\mathrm{MeOH}$ in water $(20,50,80$, and $100 \mathrm{vol} \%, 2 \mathrm{~L}$ for each fraction) to afford four fractions (F20, F50, F80, and F100, respectively) that were subjected to HPLC for further identification.

F50 was subjected to silica gel open-column chromatography using chloroform-MeOH- $\mathrm{H}_{2} \mathrm{O}$ (14:6:1 and 13:7:1, each $300 \mathrm{~mL}$ ) as an eluent to give five sub-fractions, namely F50A-F50E. F50A and F50B were obtained as pure compounds and they were compound $\mathbf{1}(7.0 \mathrm{mg})$ and $\mathbf{2}(2.7 \mathrm{mg})$. TLC was performed to monitor the collection of fractions and spots were visualized by dipping in $1 \%$ vanillin solution followed by 10 -min heating at $110{ }^{\circ} \mathrm{C}$.

F80 was subjected to preparative HPLC using a Cosmosil 5C18-MS-II column $(10 \mathrm{~mm}$ I.D. $\times 250 \mathrm{~mm}$, particle size of $5 \mu \mathrm{m}$ ) maintained at $35^{\circ} \mathrm{C}$. Preparative HPLC was performed using a Jasco PU2089 intelligent pump equipped with a Jasco UV-2075 detector (Tokyo, Japan) and a Shimadzu CTO-10ACVP column oven (Kyoto, Japan). Elution was performed with $20 \% \mathrm{MeCN}$ and $0.5 \% \mathrm{HCOOH}$ in water at a flow rate of $5.0 \mathrm{~mL} / \mathrm{min}$ to obtain $3(4.4 \mathrm{mg})$ and 4 (2.8. $\mathrm{mg})$. Chromatogram was monitored by UV absorption at wavelength of $254 \mathrm{~nm}$. The chemical structure of compounds 1-4 were determined by combination of NMR and MS/MS analysis. Determination of compounds 5-14 were performed by MS/MS analysis only.

\subsection{HPLC Condition}

F50 and F80 samples were dissolved in MeOH and injected $(5 \mu \mathrm{L})$ into a reverse-phase HPLC-PDA system consisted of Jasco PU2089 intelligent pump equipped with a JASCO MD-2010 plus detector and a Jasco CO-2065 Plus column oven (Tokyo, Japan). Reversed phase column (Cosmosil 5C18-MS-II, $4.6 \mathrm{ID} \times 150 \mathrm{~mm}$, particle size of $5 \mu \mathrm{m}$ ) was used and the temperature was controlled at $35^{\circ} \mathrm{C}$. F50 was performed using mobile phase contained $0.5 \% \mathrm{HCOOH}$ in $\mathrm{H}_{2} \mathrm{O}(\mathrm{A})$ and acetonitrile (B), and the following gradient was used: 10\% B for $10 \mathrm{~min}, 15 \%$ B at $30 \mathrm{~min}, 25 \%$ B at $45 \mathrm{~min}, 35 \% \mathrm{~B}$ at $55 \mathrm{~min}$, $45 \% \mathrm{~B}$ at $60 \mathrm{~min}$, and 55\% B at $70 \mathrm{~min}$. F80 was performed using 20\% $\mathrm{MeCN}$ and $0.5 \% \mathrm{HCOOH}$ in 
water on isocratic condition. The flow rate was set to $1 \mathrm{~mL} / \mathrm{min}$, and detection was performed at $254 \mathrm{~nm}$. Chromatograms of F50 and F80 as shown on Figure 1a,b.

\subsection{Acid Hydrolysis of $\mathbf{1}-\mathbf{4}$}

Hydrolysis was performed as described elsewhere [22]. Compounds 1-4 were dissolved in $5 \%$ aq. $\mathrm{H}_{2} \mathrm{SO}_{4}-1,4$-dioxane $(1: 1, v / v ; 1 \mathrm{~mL})$, and the solution was stirred under reflux for $2 \mathrm{~h}$, cooled, and neutralized using Amberlite IRA-400 (OH-form) (Sigma Aldrich, St. Louis, MO, USA), which was then removed by filtration. The filtrate was concentrated, and the residue was loaded on a Monospin C18 spin (GL science, Japan) column and eluted with $\mathrm{H}_{2} \mathrm{O}$ and $\mathrm{MeOH}$. The $\mathrm{H}_{2} \mathrm{O}$ eluate was concentrated, and the residue was sequentially treated with L-cysteine methyl ester hydrochloride $(3 \mathrm{mg})$ in pyridine $(0.5 \mathrm{~mL})$ at $60^{\circ} \mathrm{C}$ for $1 \mathrm{~h}$ and $\mathrm{N}, \mathrm{O}$-bis (trimethylsilyl)trifluoroacetamide $(0.2 \mathrm{~mL})$ at $60^{\circ} \mathrm{C}$ for $1 \mathrm{~h}$. The supernatant was further analyzed by GC-MS.

\subsection{GC-MS Condition}

An Agilent 6890N gas chromatograph (Agilent Technologies, Santa Clara, CA, USA) fitted with a DB-5 column (30m, $250 \mu \mathrm{m}$ I.D., film thickness $0.25 \mu \mathrm{m}$, J\&W Scientific, PA, USA) coupled to a JMS-AMSUN200/GI UltraQuad GC-MS instrument (JEOL Ltd., Tokyo, Japan) was employed. The column temperature was set to $280{ }^{\circ} \mathrm{C}$, and the He flow rate equaled $1 \mathrm{~mL} / \mathrm{min}$. The oven temperature was increased from 100 to $180{ }^{\circ} \mathrm{C}$ at $10{ }^{\circ} \mathrm{C} / \mathrm{min}$, then to $240{ }^{\circ} \mathrm{C}$ at $25^{\circ} \mathrm{C} / \mathrm{min}$, held for $10 \mathrm{~min}$, increased to $300{ }^{\circ} \mathrm{C}$ at $25^{\circ} \mathrm{C} / \mathrm{min}$ and held for $2 \mathrm{~min}$. The MS scan range equaled $50-1000$, and scanning was performed at a rate of 2 scans/s. The transfer line and ion source were held at $280^{\circ} \mathrm{C}$. The MS spectrum of each peak was identified using the library match software from the National Institute of Standards and Technology (NIST) library and compared to authentic standards.

\subsection{Ultrahigh-Performance Liquid Chromatography-Time-of-Flight Mass Spectrometry (UPLC-TOF-MS) Conditions}

Analysis was performed on an UPLC system coupled to a QTOF-MS (Waters Xevo G2 QTof, Waters, Milford, MA, USA) instrument operated in electrospray ionization (ESI) mode at a mass resolution of 20,000 and controlled by MassLynx 4.1 software. An Acquity UPLC BEH C18 column ( $2.1 \mathrm{~mm}$ I.D. $\times 100 \mathrm{~mm}, 1.7 \mu \mathrm{m}$, Waters, USA) at $35^{\circ} \mathrm{C}$ was used for chromatographic separation. The sample $(1 \mu \mathrm{L})$ was injected using an autosampler. The mass spectrometer was calibrated with $0.5 \mathrm{mM}$ sodium formate. Leucine enkephalin $(2 \mu \mathrm{g} / \mathrm{mL}, \mathrm{m} / z 556.2771$ in positive mode $)$ was used as lock spray at a flow rate of $10 \mu \mathrm{L} / \mathrm{min}$. The collision energy equaled $6 \mathrm{~V}$. The source parameters were as follows: capillary voltage $2.5 \mathrm{kV}$, sampling cone voltage $30 \mathrm{~V}$, extraction cone voltage $4 \mathrm{~V}$, source temperature $150{ }^{\circ} \mathrm{C}$, desolvation temperature $500{ }^{\circ} \mathrm{C}$, desolvation gas flow $1000 \mathrm{~L} / \mathrm{h}$, cone gas flow $50 \mathrm{~L} / \mathrm{h}$. Each compound was fragmented using a range of 25-30 V for MS/MS scans. The mobile phase contained $1 \% \mathrm{HCOOH}$ in $\mathrm{H}_{2} \mathrm{O}(\mathrm{A})$ and $\mathrm{MeCN}(\mathrm{B})$. $\mathrm{F} 50$ was separated using the following gradient: initial $10 \%$ B for $1.2 \mathrm{~min}, 15 \%$ B at $3.5 \mathrm{~min}, 25 \%$ B at $5.2 \mathrm{~min}, 35 \% \mathrm{~B}$ at $6.4 \mathrm{~min}, 45 \% \mathrm{~B}$ at $7.0 \mathrm{~min}, 55 \% \mathrm{~B}$ at $8.1 \mathrm{~min}$, hold until $10 \mathrm{~min}$. F80 was separated isocratically using $20 \%$ B for $50 \mathrm{~min}$.

\subsection{Spectroscopic Data of Compounds $\mathbf{1}-\mathbf{4}$}

3.8.1. Kaempferol 3-O- $\alpha$-L-rhamnopyranosyl $(1 \rightarrow 2)$ [ $\alpha$-L-rhamnopyranosyl $(1 \rightarrow 6)]$ - $\beta$-D-glucopyranoside-7-O- $\alpha$-L-rhamnopyranoside (1)

Yellow powder. $[\alpha]_{D}^{23}=-33.15^{\circ}(\mathrm{c}=0.70, \mathrm{MeOH})$ was performed on a Jasco P2300 digital polarimeter (Jasco Corporation, Tokyo, Japan). HR-ESI-MS: $m / z 887.2843[\mathrm{M}+\mathrm{H}]^{+}$(calcd. for $\left[\mathrm{C}_{39} \mathrm{H}_{51} \mathrm{O}_{23}\right]^{+}, 887.2821$ ) was carried out using a Waters Xevo G2 QTOF LC/MS system (Waters, Milford, MA, USA). UV $\lambda \max / \mathrm{nm}(\log \varepsilon): 267$ (4.71), 350 (4.60) were recorded on a Lambda 950 UV-vis-NIR spectrometer (Perkin Elmer, Shelton, CT, USA) in MeOH solution. IR vmax $/ \mathrm{cm}^{-1}:$ 1655, 3402 was recorded on a Spectrum 100 FT-IR spectrometer (Perkin Elmer, Shelton, CT, USA) using KBr as a matrix. 
$1 \mathrm{H}$ and $13 \mathrm{C}$ NMR spectra were recorded in $\mathrm{CD}_{3} \mathrm{OD}$ on Bruker AV800 (800 MHz) instruments (Bruker, MA, USA): see Table 1.

3.8.2. Kaempferol 3-O-(2,6-di- $\alpha$-L-rhamnopyranosyl)- $\beta$-D-glucopyranoside (2)

Yellow powder. $[\alpha]_{D}^{23}=-32.15^{\circ}(c=0.27, \mathrm{MeOH})$. HR ESI-MS: $m / z 741.2214[\mathrm{M}+\mathrm{H}]^{+}$(calcd. for $\left.\left[\mathrm{C}_{33} \mathrm{H}_{41} \mathrm{O}_{19}\right]^{+}, 741.2242\right)$. UV $\lambda_{\max } / \mathrm{nm}(\log \varepsilon): 268$ (4.87), 348 (4.63). IR $v_{\max } / \mathrm{cm}^{-1}: 1657,3402 .{ }^{1} \mathrm{H}$ and ${ }^{13} \mathrm{C}$ NMR $\left(\mathrm{CD}_{3} \mathrm{OD}\right)$ : see Table 1.

3.8.3. Kaempferol 3-O- $\alpha$-L-rhamnopyranosyl ( $1 \rightarrow 6)$ - $\beta$-D-glucopyranosyl

$(1 \rightarrow 2)$ - $\beta$-D-galactopyranosyl-7-O-[3-O-o-anisoyl]- $\alpha$-L-rhamnopyranoside (3)

Yellow powder. $[\alpha]_{D}^{23}=-64.77^{\circ}(c=0.44, \mathrm{MeOH})$. HR ESI-MS: $m / z$ 1037.3076 $[\mathrm{M}+\mathrm{H}]^{+}$(calcd. for $\left.\left[\mathrm{C}_{47} \mathrm{H}_{57} \mathrm{O}_{26}\right]^{+}, 1037.3138\right)$. UV $\lambda_{\max } / \mathrm{nm}(\log \varepsilon): 268$ (5.10), 349 (4.96). IR $v_{\max } / \mathrm{cm}^{-1}: 1602,3436 .{ }^{1} \mathrm{H}$ and ${ }^{13} \mathrm{C}$ NMR $\left(\mathrm{CD}_{3} \mathrm{OD}\right)$ : see Table 1.

3.8.4. Kaempferol 3-O-(2,6-di- $\alpha$-L-rhamnopyranosyl)- $\beta$-D-galactopyranoside-7-O-[3-O-o-anisoyl]$\alpha$-L-rhamnopyranoside (4)

Yellow powder. $[\alpha]_{D}^{23}=-161.64^{\circ}(\mathrm{c}=0.28, \mathrm{MeOH})$. HR ESI-MS: $m / z 1021.3170[\mathrm{M}+\mathrm{H}]^{+}$(calcd. for $\left.\left[\mathrm{C}_{47} \mathrm{H}_{57} \mathrm{O}_{25}\right]^{+}, 1021.3189\right)$. UV $\lambda \max / \mathrm{nm}(\log \varepsilon): 268$ (5.15), 345 (5.01). IR vmax $/ \mathrm{cm}^{-1}: 1601,3430$. $1 \mathrm{H}$ and 13C NMR spectra were recorded in $\mathrm{CD}_{3} \mathrm{OD}$ on Bruker AV600 (600 MHz) instruments (Bruker, Massachusetts, USA): see Table 1.

\subsection{Quantitative Analysis}

F50 and F80 samples were dissolved in methanol to a concentration of $10 \mathrm{mg} / \mathrm{mL}$, and the solutions were injected $(20 \mu \mathrm{L})$ into a reverse-phase HPLC-PDA system described above. The mobile phase comprised $0.5 \% \mathrm{HCOOH}$ in $\mathrm{H}_{2} \mathrm{O}(\mathrm{A})$ and $0.5 \% \mathrm{HCOOH}$ in acetonitrile (B), and the following gradient was used: initial 10\% B for $10 \mathrm{~min}, 15 \% \mathrm{~B}$ at $30 \mathrm{~min}, 25 \% \mathrm{~B}$ at $45 \mathrm{~min}, 35 \% \mathrm{~B}$ at $55 \mathrm{~min}, 45 \% \mathrm{~B}$ at $60 \mathrm{~min}$, and $55 \% \mathrm{~B}$ at $70 \mathrm{~min}$. The flow rate was set to $1 \mathrm{~mL} / \mathrm{min}$, and detection was performed at $330 \mathrm{~nm}$ corresponds to the absorbance of the flavonol backbone. Quantification was performed using the area under each peak determined by ChromNAV software (JASCO, Tokyo, Japan). Kaempferol compounds diluted in methanol with concentrations of $0.0017,0.0035,0.0175,0.0349,0.1747,0.3494$, and $3.4937 \mu \mathrm{M}$ were used as standards. The content of each compound was expressed as milligram per $100 \mathrm{~g}$ dry flour weight.

\subsection{In Vitro $\alpha$-Glucosidase Inhibition Activity}

The $\alpha$-glucosidase inhibitory activity was assayed in vitro using a 96-well plate as reported earlier [30] with Versa max microplate reader (Molecular Devices, San Jose, CA, USA). Briefly, $1 \mathrm{mg}$ of each sample and acarbose were dissolved in $20 \%$ of DMSO in phosphate buffer $(50 \mathrm{mM}$, pH 6.9). The $50 \mu \mathrm{L} /$ well of sample solution mixed with $20 \mu \mathrm{L} /$ well of $\alpha$-glucosidase $(0.5 \mathrm{U} / \mathrm{mL}$; diluted in phosphate buffer) from Saccharomyces cereviceae (Type I, Sigma-Aldrich, St. Louis, MO, USA). After preincubated at $37^{\circ} \mathrm{C}$ for $15 \mathrm{~min}$, the assay was initiated by adding $50 \mu \mathrm{L} /$ well of 4-nitrophenyl- $\alpha$-D-glucopyranoside (PNPG) $(9 \mathrm{mg} / \mathrm{mL}$; diluted in phosphate buffer) as a substrate. Then, the mixture was incubated further at $37^{\circ} \mathrm{C}$ for $15 \mathrm{~min}$. The reaction was stopped by adding $100 \mu \mathrm{L} /$ well of $\mathrm{Na}_{2} \mathrm{CO}_{3}$ (100 mM; diluted in phosphate buffer). The absorbance of the released $p$-nitrophenol was measured at $415 \mathrm{~nm}$. Solution of $20 \%$ DMSO in phosphate buffer was set up as a control and each experiment was performed in triplicate. The results were expressed as percent inhibition and calculated using the formula:

$$
\text { inhibitory activity }(\%)=(1-(\text { Abs sample/Abs control }) \times 100 \%
$$


Statistical analysis was performed using the analysis of variance (ANOVA) and the Tukey's HSD post hoc test carried out at significance level of $p<0.05$ to determine differences between the samples using Past 4.0 software (Oslo, Norway) [31].

\section{Conclusions}

To enhance the added value and expand the application scope of jack bean, we focused on the isolation and identification of polyphenols contained in this legume. As a result, four kaempferol glycosides were isolated, one of which was novel, while the others have not been previously found in jack bean. Furthermore, ten more compounds (all of them kaempferol glycosides) were identified by LC-MS/MS. These compounds were exhibited by the inhibition activity of $\alpha$-glucosidase. The presence of anisoyl group in the kaempferol glycosides made these compounds potential for preventing diabetes. These results suggested that jack bean can be utilized as a raw ingredient for foods and a possible source of functional compounds. These findings highlight the importance of daily flavonoid intake with food and demonstrating that jack bean is a potential source of flavonoids, especially kaempferol. Furthermore, these suggestions also underscore the necessity of investigating the effects of the food processing applied. Considering these bioactive compounds were usually unstable under heating condition, the proper application of this bean as a food ingredient need to be found for the optimum efforts to reduce levels of antinutritional compounds and minimize degradation of these bioactive compounds.

Supplementary Materials: The following are available online at http://www.mdpi.com/1420-3049/25/11/2481/s1, Figure S1-S5: HR-ESI-MS, 1H, 13C NMR, COSY, HSQC, HMBC of 1, Figures S6-S10: Spectra of 2, Figures S11-S15: Spectra of 3, Figures S16-S20: Spectra of 4, Figure S21-S34: LC/ESI/MS/MS data of compounds 1-14, Figure S35-S37: GC-MS total ion chromatogram and extracted ion chromatogram of trimethylsilyl (TMS) derivatives of galactose, glucose and rhamnose; Figure S38-S41: GC-MS total ion chromatogram and extracted ion chromatogram trimethylsilyl (TMS) derivatives of compounds 1-4. Figure S42-S43: Chromatogram of compounds 1-4.

Author Contributions: A.M.S, E.Y., I.B., D.F., and H.N.L., conceived and designed the experiment; A.M.S., implemented the experiments; A.M.S. and E.Y., analyzed the data and wrote the original draft; E.Y., helped in experiments and contributed reagents/material and analysis tools; I.B., D.F., and H.N.L., supervision; A.M.S., E.Y., I.B., D.F., and H.N.L., wrote, reviewed and edited the manuscript. All authors have read and agreed to the published version of the manuscript.

Funding: This research received no external funding.

Acknowledgments: We thank Yoshiharu Sawada (Division of Instrumental Analysis, Life Science Research Center, Gifu University) for technical support with NMR experiments.

Conflicts of Interest: The authors declare no conflicts of interest.

\section{References}

1. International Diabetes Federation. IDF Diabetes Atlas, 9th ed.; International Diabetes Federation: Brussels, Belgium, 2019; ISBN 978-2-930229-87-4.

2. BischoffAg, H.B.B. Pharmacology of $\alpha$-glucosidase inhibition. Eur. J. Clin. Investig. 2010, 24, 3-10. [CrossRef]

3. Kumar, V.; Prakash, O.; Kumar, S.; Narwal, S. $\alpha$-glucosidase inhibitors from plants: A natural approach to treat diabetes. Pharmacogn. Rev. 2011, 5, 19-29. [CrossRef]

4. Murad, M.H.; Coto-Yglesias, F.; Wang, A.T.; Sheidaee, N.; Mullan, R.J.; Elamin, M.B.; Erwin, P.J.; Montori, V.M. Drug-Induced Hypoglycemia: A Systematic Review. J. Clin. Endocrinol. Metab. 2009, 94, 741-745. [CrossRef]

5. Marín-Peñalver, J.J.; Martín-Timón, I.; Sevillano-Collantes, C.; Del Cañizo-Gómez, F.J. Update on the treatment of type 2 diabetes mellitus. World J. Diabetes 2016, 7, 354-395. [CrossRef] [PubMed]

6. Ramachandran, V.; Xu, B. Antidiabetic properties of dietary flavonoids: A cellular mechanism review. Nutr. Metab. 2015, 12, 60. [CrossRef]

7. Kim, Y.; Keogh, J.B.; Clifton, P.M. Polyphenols and Glycemic Control. Nutrients 2016, 8, 17. [CrossRef]

8. Ade-Omowaye, B.I.O.; Tucker, G.A.; Smetanska, I. Nutritional Potential of Nine Underexploited Legumes in Southwest Nigeria. Int. Food Res. J. 2015, 22, 798-806. 
9. Doss, A.; Pugalenthi, M.; Vadivel, V. Nutritional Evaluation of Wild Jack Bean (Canavalia ensiformis DC) Seeds in Different Locations of South India. World Appl. Sci. J. 2011, 13, 1606-1612.

10. Chel-Guerrero, L.A.; Delgado-Herrera, A.; Betancur-Ancona, D.A.; Pérez-Aviña, P.; Castellanos-Ruelas, A.F. Protein and Energy Evaluation of Detoxified Canavalia Seeds as a Feedstuff for Poultry in the Tropics. Nov. Sci. 2016, 8, 219-232.

11. Vadivel, V.; Biesalski, H.K. Effect of certain indigenous processing methods on the bioactive compounds of ten different wild type legume grains. J. Food Sci. Technol. 2011, 49, 673-684. [CrossRef]

12. Doss, A.; Pugalenthi, M.; Vadivel, V.G.; Subhashini, G.; Anitha Subash, R. Effects of Processing Technique on the Nutritional Composition and Antinutrients Content of Under-utilized Food Legume Canavalia ensiformis L. DC. Int. Food Res. J. 2011, 18, 965-970.

13. Akpapunam, M.; Sefa-Dedeh, S. Some physicochemical properties and anti-nutritional factors of raw, cooked and germinated Jack bean (Canavalia ensiformis). Food Chem. 1997, 59, 121-125. [CrossRef]

14. Akande, K. Effects of Anti-nutritive Constituents of Unprocessed Jack Bean (Canavalia ensiformis) (L) (DC) Seed Meal on Poultry Performance. Am. J. Exp. Agric. 2016, 10, 1-10. [CrossRef]

15. Akande, K.; Fabiyi, E. Effect of Processing Methods on Some Antinutritional Factors in Legume Seeds for Poultry Feeding. Int. J. Poult. Sci. 2010, 9, 996-1001. [CrossRef]

16. Belmarl, R.; Nava-Montero, R.; Sandoval-Castro, C.; McNab, J.M. Jack Bean (Canavalia ensiformis L. DC) in Poultry Diets: Antinutritional Factors and Detoxification Studies-A Review. World's Poult. Sci. J. 1999, 55, 37-59. [CrossRef]

17. Olugboyega, S.K.; Edem, A.R. Comparative Phytochemicals and In Vitro Antioxidative Effects of Jack Beans (Canavalia ensiformis) and Sword Beans (Canavalia gladiata). Ann. Food Sci. Technol. 2018, 19, 499-505.

18. Sowndhararajan, K.; Siddhuraju, P.; Manian, S.; Sowndhararajan, K. Antioxidant activity of the differentially processed seeds of Jack bean (Canavalia ensiformis L. DC). Food Sci. Biotechnol. 2011, 20, 585-591. [CrossRef]

19. Vadivel, V.; Cheong, J.; Biesalski, H. Antioxidant and type II diabetes related enzyme inhibition properties of methanolic extract of an underutilized food legume, Canavalia ensiformis (L.) DC: Effect of traditional processing methods. LWT 2012, 47, 255-260. [CrossRef]

20. Kite, G.C.; Stoneham, C.; Veitch, N.C. Flavonol tetraglycosides and other constituents from leaves of Styphnolobium japonicum (Leguminosae) and related taxa. Phytochemistry 2007, 68, 1407-1416. [CrossRef]

21. Kazuma, K. Malonylated flavonol glycosides from the petals of Clitoria ternatea. Phytochem. 2003, 62, $229-237$. [CrossRef]

22. Murakami, T.; Kohno, K.; Kishi, A.; Matsuda, H.; Yoshikawa, M. Absolute Stereostructures of Canavalioside, a New Ent-kaurane-type Diterpene Glycoside and Gladiatosides A1, A2, A3, B1, B2, B3, C1 and C2, New Acylated Flavonol Glycosides, From Sword Bean, the Seeds of Canavalia gladiata. Chem. Pharm. Bull. 2000, 48, 1673-1680. [CrossRef]

23. Kachlicki, P.; Piasecka, A.; Stobiecki, M.; Marczak, Ł. Structural Characterization of Flavonoid Glycoconjugates and Their Derivatives with Mass Spectrometric Techniques. Molecules 2016, 21, 1494. [CrossRef]

24. Stobiecki, M.; Skirycz, A.; Kerhoas, L.; Kachlicki, P.; Muth, D.; Einhorn, J.; Mueller-Roeber, B. Profiling of phenolic glycosidic conjugates in leaves of Arabidopsis thaliana using LC/MS. Metabolomics 2006, 2, 197-219. [CrossRef]

25. Ma, Y.-L.; Cuyckens, F.; Heuvel, H.V.D.; Claeys, M. Mass spectrometric methods for the characterisation and differentiation of isomeric O-diglycosyl flavonoids. Phytochem. Anal. 2001, 12, 159-165. [CrossRef] [PubMed]

26. Cuyckens, F.; Rozenberg, R.; De Hoffmann, E.; Claeys, M. Structure characterization of flavonoid O-diglycosides by positive and negative nano-electrospray ionization ion trap mass spectrometry. J. Mass Spectrom. 2001, 36, 1203-1210. [CrossRef]

27. Ferreres, F.; Andrade, P.B.; Valentão, P.; Gil-Izquierdo, A. Further knowledge on barley (Hordeum vulgare L.) leaves O-glycosyl-C-glycosyl flavones by liquid chromatography-UV diode-array detection-electrospray ionisation mass spectrometry. J. Chromatogr. A 2008, 1182, 56-64. [CrossRef] [PubMed]

28. Xiao, J.; Kai, G.; Yamamoto, K.; Chen, X. Advance in Dietary Polyphenols as $\alpha$-Glucosidases Inhibitors: A Review on Structure-Activity Relationship Aspect. Crit. Rev. Food Sci. Nutr. 2013, 53, 818-836. [CrossRef]

29. Kim, J.-S.; Kwon, C.-S.; Son, K.H. Inhibition of Alpha-glucosidase and Amylase by Luteolin, a Flavonoid. Biosci. Biotechnol. Biochem. 2000, 64, 2458-2461. [CrossRef] 
30. Sutedja, A.M.; Yanase, E.; Batubara, I.; Fardiaz, D.; Lioe, H.N. Antidiabetic components from the hexane extract of red kidney beans (Phaseolus vulgaris L.): Isolation and structure determination. Biosci. Biotechnol. Biochem. 2019, 84, 598-605. [CrossRef] [PubMed]

31. Hammer, O.; Harper, D.A.T.; Ryan, P.D. PAST: Paleontological Statistics Software Package for Education and Data Analysis. Palaeontol. Electron. 2001, 4, 9.

Sample Availability: Samples of the compounds are not available from the authors.

(C) 2020 by the authors. Licensee MDPI, Basel, Switzerland. This article is an open access article distributed under the terms and conditions of the Creative Commons Attribution (CC BY) license (http://creativecommons.org/licenses/by/4.0/). 